\title{
Revisão teórica que fundamenta pesquisa sobre a complexidade observada em arranjos e operações interorganizacionais
}

\author{
Miguel Afonso Sellito, Dr. \\ Mestrado em Engenharia de Peodução e Sistemas - UNISINOS \\ msellitto@unisinos.br
}

Miriam Borchardt, Dr.

Mestrado em Engenharia de Peodução e Sistemas - UNISINOS

miriamb@unisinos.br

\author{
Giancarlo Medeiros Pereira, Dr. \\ Mestrado em Engenharia de Peodução e Sistemas - UNISINOS \\ gian@unisinos.br
}

\begin{abstract}
Este artigo apresenta a revisão bibliográfica que formou o marco teórico de pesquisas já em andamento que propuseram um método para a avaliação e eventual controle da complexidade em operações produtivas realizadas em arranjos organizacionais, tais como cadeias de suprimentos e redes de cooperação. O método surge nas publicações dos primeiros achados de pesquisa, referenciado neste artigo. Havendo um indicador que informe a complexidade do arranjo, as fontes de complexidade e suas contribuições para a complexidade total, um gestor poderá decidir se a aumenta, reduz ou mantém, em uma lógica de controle estratégico. O artigo descreve e contextualiza o pensamento complexo no ambiente organizacional e revisa teorias antecedentes, tais como a causação não-linear, a teoria dos sistemas, a teoria da informação, a auto-organização, a cibernética, a teoria do caos, a autopoiese e as estruturas dissipativas. Ao fim, são apresentadas as direções da pesquisa que já está em andamento.
\end{abstract}

Palavras-chave: complexidade; sistemas complexos adaptativos; cibernética; teoria da informação; avaliação de complexidade

This paper presents a theoretical review that is the foundation of research in searching of a method for assessing and eventually controlling the complexity in interorganizational arrays, like supply chains and networks. The method is presented in the publications of the initial findings, referred in this paper. Based on an indicator that informs the amount of complexity, their sources and partial contribution, a manager can decide about increasing, reducing or even sustaining that complexity, in a strategic perspective. The paper describes and contextualizes the complex thinking in the organizational environment and review perspectives, like the non-linear causation, systemic theory, self-organized systems, information theory, cybernetics, chaos, autopoiesis and dissipative structures. At the end, we present the directions for the research already in motion

Key-words: complexity; adaptive complex systems; cybernetics; information theory; complexity assessment

\section{Introdução}

O pensamento científico clássico se edificou sobre as noções de ordem, separação causa-efeito e razão absoluta. No âmbito do pensamento clássico, os cientistas têm tentado explicar o universo como um conjunto de sistemas que seguem caminhos reversíveis e previsíveis, explicados por combinações lineares e relações causa-efei- to determinísticas e unívocas. Tais relações são deduzidas sob as noções de ordem, razão e regularidade. Estes pilares têm sido desafiados pela ciência contemporânea, que tem admitido a coexistência de ordem e desordem, que partes de objetos não são separáveis sem que se destrua o objeto e que a lógica da razão pura também pode gerar 
contradições. No pensamento complexo, ou teoria da complexidade, ordem, separação e razão não se contrapõem a desordem, inseparabilidade e não-razão, mas os agregam em combinação entre contrários que dialogam continuamente entre si, a dialógica (MORIN e Le MOIGNE, 2000).

A teoria da complexidade nasceu do esforço transdisciplinar de pesquisadores e pode ser considerada uma transição entre dois paradigmas de ciência. O primeiro inclui a ciência clássica e linear, que simplifica a realidade e reduz o objeto de estudo aos seus elementos constituintes para análise e comunicação de achados. O segundo também é chamado de pensamento complexo e inclui uma ciência não-linear que evita a simplificação e estuda o objeto em seu todo, incluindo as interações mútuas que surgem entre as partes e formam a sua complexidade (BARYAM, 1997).

Um elemento central na teoria da complexidade é a noção de sistema adaptativo complexo (SAC).

Sistemas surgem quando elementos independentes se inter-relacionam e das inter-relações surgem situações de interesse científico. Os aspectos de interesse dos sistemas podem ser descritos por variáveis numéricas, as variáveis de estado: o estado de um sistema em um dado tempo é o conjunto dos valores assumidos neste tempo pelas variáveis de estado. Se o estado futuro do sistema resulta da interação entre elementos independentes, e não for possível deduzi-lo ou prevê-lo por equações determinísticas, então é dito sistema adaptativo complexo (GLEISER, 2002).

No âmbito do pensamento complexo, a não-linearidade e o papel criativo da desordem explicam as trajetórias irreversíveis e os resultados imprevisíveis apresentados pelos SAC's, as emergências. Emergências são propriedades e capacidades ausentes nas partes, mas presentes quando estas se reorganizam, adaptando-se a um fator externo que desordena e modifica as relações vigentes no sistema. A desordem externa provoca uma nova e emergente ordem interna. O comportamento emergente não pode ser deduzido do comportamento das partes nem do comportamento passado do sistema. O modo como as partes se reorganizam após eventos desordenadores é inesperado, resultando estados imprevistos e rotas irreversíveis. Prever o comportamento de um SAC é improvável(HEYLIGHEN, 1988).

À primeira vista, a complexidade surge como fenômeno quantitativo em um SAC: é a quantidade de informação necessária para descrever as interações e interferências mútuas entre as partes e que despertam um interesse de pesquisa (BAR-YAM, 1997). Mas a complexidade também reside na incerteza entre as interações e na quantidade de desordem e ordem que nelas convivem e é mais do que mistura estatística. Nesta, chega-se à ordem das po- pulações observando e operando sobre a desordem das amostras. Naquela, partes do sistema interagem e geram comportamentos contra-intuitivos e não-lineares, inexistentes nas partes, e que voltam a desaparecer com a separação. É impossível entender a complexidade de um objeto ou sistema pelo simples entendimento de suas partes isoladas ou de amostras de seu conteúdo (PERONA e MIRAGLIOTTA, 2004; DEMO, 2002; MORIN, 1990; RUELLE, 1993).

Definições para a complexidade de sistemas surgem na literatura. Sterman (2000) define complexidade como o número de componentes, variáveis ou estados que um sistema pode assumir ou o número de combinações entre variáveis que devam ser consideradas em um problema de decisão. $\mathrm{O}$ autor diferencia e explora a diferença entre complexidade dinâmica e complexidade de detalhes, sendo dada ênfase à complexidade dinâmica na Dinâmica de Sistemas, desde suas fontes até seu tratamento. Este é um conceito importante para a dinâmica de sistemas, que é uma das escolas do pensamento sistêmico. Para Klir (1991), complexidade é o número de variáveis, estados, partes, relações e interações ativas no sistema. Maximiano (1997) diz que a complexidade indica o número de situações e variáveis, os estados, com o qual um sistema pode se deparar na trajetória de seus processos. $\mathrm{O}$ autor caracteriza-a por: (i) nenhum problema é totalmente linear; (ii) não existe efeito que resulte de uma única causa nem uma causa que produza um único efeito; e (iii) quanto mais variáveis relevantes para a situação de interesse, mais interdependências mútuas há no sistema. Schoderbek et al. (1975, apud JACKSON, 1993) diz que a complexidade de um sistema é influenciada pelo número de partes reconhecíveis, intensidade de interação e regras de organização entre estas.

Morin e Le Moigne (2000) distinguem complexidade e complicação. Esta denota elementos imbricados que podem ser separados sem ambigüidades, incertezas, ambivalências ou perda da individualidade, tal como uma roda de bicicleta, enquanto que aquela denota relações ambíguas e imprevisíveis, tais como as que ocorrem em grupos humanos. Morin (1990) observa três facetas da complexidade: (i) conhecimentos sobre partes não ajudam a prever o todo - o todo é mais do que a soma das partes; (ii) partes juntas podem inibir qualidades individuais de outras partes - o todo é menos do que a soma das partes; e (iii) as facetas anteriores ocorrem juntas - o todo é, ao mesmo tempo, mais e menos do que a soma das partes. Morin e Le Moigne (2000) apontam como via de acesso a uma teoria da complexidade as chamadas três teorias: a teoria da informação, a cibernética e os sistemas adaptativos complexos. Abraham (2002, apud LEITE et al., 2004) acrescenta a teoria do caos. A teoria da complexidade é chamada por Parker e Stacey (1995) de dinâmica não-linear. 
O objetivo deste artigo foi apresentar o marco teórico que foi usado em pesquisas sobre a complexidade observada em operações e arranjos interorganizacionais, tais como cadeias de suprimentos e redes de cooperação. Achados iniciais de pesquisa foram publicados em Sellitto, Borchardt e Pereira (2007; 2008). Nestas, é apresentado e detalhado o método de pesquisa que foi desenvolvido, fundamentado na presente revisão. Outros achados encontram-se em processo de comunicação. A utilidade deste marco está em agregar, para consulta e revisão, em um documento unificado, conteúdos disponíveis em várias fontes, de campos de conhecimento diversificados, tais como as ciências naturais, administrativas e sociais: os pesquisadores sentiram a necessidade de condensar, para facilidade de consulta e divulgação, os vários referenciais teóricos usados na pesquisa. A contribuição que esta revisão pode dar diz respeito ao tratamento das relações interinstitucionais que surgem quando várias empresas entidades ou partes de organizações decidem, estrategicamente, operar de modo colaborativo para perseguir objetivos comuns. É objetivo das teorias que compõem o paradigma sistêmico-complexo buscar a compreensão e o gerenciamento das inter-relações que surgem entre as partes componentes de um sistema, tais como as relações interorganizacionais de produção.

Foram revisadas: linearidade, não-linearidade, causalidade, sistemas adaptativos complexos, cibernética, teoria do caos, autopoiese e estruturas dissipativas.

\section{Linearidade, não-linearidade e causação}

A ciência clássica tem tentado explicar o comportamento de sistemas por aproximações lineares ou lineares por segmentos. Em uma relação linear, há um efeito para uma causa, uma causa para um efeito e o efeito combinado de duas causas é a soma dos efeitos de cada uma. Há proporcionalidade e separabilidade: a intensidade do efeito cresce segundo a intensidade da causa, pode-se separar o sistema em partes, estudá-las isoladamente e recompôlo, sem perda de conteúdo.

A linearidade pode ser representada pelo processo $y(x)=$ $a . x^{n}+b, n$ inteiro. Se $n=1, y(x)$ é uma reta e a cada efeito $y(x)$ corresponde linearmente uma e apenas uma causa $x$. Na relação não-linear, várias causas podem produzir o mesmo efeito. $\operatorname{Em} y(x)=a \cdot x^{n}+b$, se $n$ é par, cada efeito $y(x)$ pode resultar de mais de uma causa $x$, ou seja, a nãolinearidade não é reversível: dado o efeito, não é possível retornar à causa, pois mais de uma causa é possível. Se $n$ é ímpar e maior do que 1, não há proporcionalidade, pois o efeito cresce exponencialmente com a causa. A nãolinearidade também admite incertezas: a mesma causa pode produzir mais de um efeito e o mesmo efeito pode ter sido originado por mais de uma causa (PARKER e STACEY,
1995; PEAKe FRAME, 1994).

Há sinergias em sistemas não-lineares: o resultado pode ser maior ou menor do que a soma das partes. Tais sistemas são imprevisíveis, pois o resultado de uma ação não é garantido e uma aproximação linear só é válida se a sinergia for irrelevante. Para explicar sinergias e interações em sistemas complexos, interessa examinar o fenômeno da causação, tanto a linear como a complexa.

\subsection{Causação linear}

Na Grécia antiga, filósofos pré-socráticos construíram uma visão cosmológica, segundo uma ordem natural governada por princípios e leis relacionando fenômenos a forças previsíveis. Os pré-socráticos distinguiam as aparências, percebidas pelos sentidos, da essência, percebida pela inteligência. Seu método de investigação era a especulação racional dos princípios ordenadores da natureza: explicações para os fenômenos naturais e suas conexões causais. Para estes filósofos, explicar o fenômeno era relacionar um efeito a uma causa que o antecede e o determina, em nexo causal. A explicação era regressiva: uma causa requer outra causa anterior, até chegar a uma situação inexplicável, a arquè, o elemento primordial que inicia a cadeia de causas e efeitos. Tal processo, ordenado e harmonioso, o kosmos, se organizava em hierarquias. A causalidade era a lei principal. O oposto era o kaos. Mais tarde, Aristóteles introduziu a empiria na explicação da natureza ao analisar a realidade através de suas partes observáveis, postulando princípios mais amplos, logicamente encadeados, que explicam as observações da realidade por quatro tipos de causas: as causas material, formal, eficiente e final. As duas primeiras explicavam a construção física e lógica do objeto, a terceira a sua lei interna de governo e a quarta o efeito de sua ação. Ao explicar um objeto também por seu efeito, Aristóteles introduziu a circularidade no raciocínio causal (SOUZA FILHO, 2000; KÖCHE, 2003; ALMEIDA, 2003).

Segundo Cirne-Lima (2003), é devido a Aristóteles e principalmente a Tomás de Aquino, que grande parte da tradição filosófica e praticamente toda a ciência moderna assumiram como pressuposto, a partir do século XIII, uma concepção de mundo que separa a causa causante e o efeito causado. Tal concepção firmou o conceito linear de causa-efeito: a causa seria diferente, lógica e ontologicamente anterior ao efeito. Se este tornar-se uma causa, então esta produzirá um novo e ulterior efeito, fora dela e depois dela, em uma cadeia linear e unidirecional de causas, efeitos, novas causas e novos efeitos. Foram os empiristas da idade moderna, principalmente Bacon e Galileu, que consolidaram a idéia da linearidade: uma causa, um efeito; mais causa, mais efeito; sem causa, sem efeito(SOUZA FILHO, 2000).

A linearidade descreve fenômenos estudados por outras 
ciências, tais como administração, economia ou engenharia, do mesmo modo que Newton descreveu o movimento dos planetas. A mecânica newtoniana aceita a existência de equilíbrio estável e a resposta a um estímulo externo, tal como a aplicação de uma força a um corpo, é proporcional ao estímulo e pode ser prevista com precisão. O método newtoniano descreveu as interferências gravitacionais entre dois corpos, principalmente quando a relação entre eles é imensamente assimétrica, tal como entre o Sol e os planetas, mas não descreveu as relações entre três ou mais corpos de tamanho equivalente. No século XIX, Poincarè observou que este problema pode comportar mais de uma solução, pois apresenta dependência exagerada em relação ao estado inicial do sistema (GLEISER, 2002).

A mecânica newtoniana e o modelo linear podem ser representados por mecanismos de relojoaria ou por autômatos. Seus componentes e sub-sistemas se integram em harmonia, podem ser separados para estudo, remontados ou até mesmo substituídos sem perda de conteúdo e sem perda de desempenho operacional. Pequenas alterações podem ser compensadas e o sistema volta ao estado de equilíbrio. Baseado no modelo linear, Laplace afirmou que, conhecida a velocidade, posição e as forças atuantes em todos os corpos do universo, é possível calcular o passado, conhecer o presente e prever o futuro. No modelo, o atual estado de um sistema é decorrente dos estados passados: passado, presente e futuro seguem relações causa-efeito exatas, em sucessão de estados simétrica e equilibrada (GLEISER, 2002).

\subsection{Causação complexa}

A exatidão obtida pelo método científico inspirou os cientistas do século XIX a acreditar que a ciência houvesse alcançado a objetividade plena e se tornado o espelho fiel da realidade, como justificado por Kant na obra Crítica da razão pura, de 1787. No alvorecer do século XX, no entanto, surgiu, na física quântica e nas teorias da relatividade de Einstein, a ruptura que desbancou o valor absoluto das noções de tempo e espaço, consolidada no princípio da incerteza de Heisenberg. O fim da objetividade, pura e isenta, modificou a ciência, tornando-a, além da objetiva descritora, uma flexível interpretadora da realidade. Ampliou-se a noção de causação linear para causação complexa, que passou a incluir as noções de probabilidade e de auto-organização.

A noção de probabilidade admite múltiplas causas para um mesmo efeito, segundo uma distribuição de probabilidades. A probabilidade permite a expansão lateral da causalidade linear, pela influência de múltiplas causas no mesmo efeito. A hierarquia dos pré-socráticos passa a expressar-se por estruturas em forma de árvore, em que múltiplas causas contribuem para um efeito que, somado a outros efeitos, influencia um efeito posterior, e assim por diante. Caso os ramos da árvore possam ser separados sem perda de conteúdo, é causalidade linear múltipla. Caso a árvore descreva o comportamento de subsistemas dentro de subsistemas maiores, cessa o potencial explicativo da causalidade linear, penetrando-se na causalidade complexa. Neste caso, mesmo havendo uma distribuição de influência para os ramos da árvore, a supressão ou inclusão de um ramo interfere nos demais e reconfigura a hierarquia (SIMON, 1991). Segundo Rapoport (1976), em complexidade organizada, uma nova parte inaugura relações com as partes atuais e altera as relações existentes.

A outra noção presente na causação complexa é a autoorganização. Von Foerster (1960, apud McCARTHY, 2004) define-a como a capacidade que um sistema tem de aumentar sua ordem ou regularidade. Para o autor, a autoorganização resulta da interação com o meio, em processos de autoprodução e automanutenção, e permite que um sistema se adapte, regenere-se, desenvolva-se e evolua, segundo informações captadas no meio e processadas por uma inteligência, que reorganiza as partes segundo o objetivo e as circunstâncias. Para Cirne-Lima (2003), a auto-organização constrói objetos não mecanísticos, mas auto-organizados dialeticamente pela causa sui, a noção platônica da razão suficiente para a existência do objeto. Segundo o autor, um sistema auto-organizado se retrodetermina, realimenta-se com informações, recompõese e se reorganiza plasticamente captando energia no meioambiente; é seletivo nas interações, pode se replicar e se reproduzir e, se afastado do equilíbrio, engendra novas formas de organização e de comportamento, de modo a buscar um novo ponto de equilíbrio.

Segundo Wiener (1948, apud CIRNE-LIMA, 2003), se a série causal fletir-se sobre si mesma, o último efeito passa a ser a primeira causa de uma série finita, surgindo uma série circular auto-organizada. Ao reduzir-se a série causal, a causa produz o efeito que produz a causa; ao fim, a causa seria a causa dela mesma, recuperando a noção platônica de causa sui. Para Cirne-Lima (2003), a autoorganização é caracterizada, entre outros aspectos, por: (i) a série causal se fechar sobre si mesma [causa $1^{3}$ efeito $1 \ldots{ }^{3}$ causa $n^{3}$ efeito $n^{3}$ causa 1]; (ii) a interação com o meio é seletiva, ou seja, o sistema escolhe, dentre as possibilidades de interação, as que contribuam para a estabilidade ou evolução; e (iii) sistemas auto-organizados podem se auto-dissipar quando não há alternativa de estabilidade. Finalizando, a auto-organização tem seu núcleo duro na relação causa-efeito circular, a auto-causação, ao contrário da mecanística, que o tem na causalidade linear.

Por fim, agrega-se a visão de Morin (1990). O autor considera que, quando uma organização produz resultados, autoproduz-se, na medida em que auto-eco-organiza-se, auto-repara-se para a tarefa e automodifica-se para se adaptar ao meio. Na auto-produção, surgem três tipos de cau- 
salidade: (i) linear, se uma entrada é transformada em produto; (ii) circular retroativa, se informações sobre o resultado de um processo são realimentadas e modificam o processo; e (iii) recursiva, se o produto é necessário ao processo que o gera. Nesta última, o produto não existe sem o produtor, que, por sua vez não existe sem o produto. Seja, por exemplo, um grupo social em um bairro que demande um serviço de transporte coletivo de passageiros. Organizado o serviço, outros grupos se mudam para o bairro, aumentando a demanda por serviço, que é ampliado. O serviço de transporte só existe porque há grupos que, ao mesmo tempo, produzem e são produzidos pelo serviço.

Interpretando livremente os autores citados, sugere-se que: (i) problemas metodológicos em sistemas complexos adaptativos exigem mais generalidade e mais rigorismo do que pode oferecer o reducionismo; e (ii) a causalidade linear, em contexto auto-organizante, é um caso particular da causação complexa.

\section{Sistemas adaptativos complexos}

O estudo de sistemas adaptativos complexos (SAC) tem sido aceito como disciplina unificada que resulta de esforços em campos tão díspares quanto a físico-química, a biologia, a administração ou a antropologia. Há universalidade no comportamento complexo, independente da atomística dos sistemas (GLEICK, 1990). O princípio da auto-organização e a noção de emergência, por exemplo, surgiram em esforços de pesquisas em diferentes campos. A ciência da complexidade considera que SAC's naturais ou artificiais, físicos, biológicos ou sócio-econômicos podem ser caracterizados por princípios unificados (BAR-YAM, 1997; MARKOSE, 2005; HEYLIGHEN, 1988). O elo de ligação entre as disciplinas é a teoria geral de sistemas (BOULDING, 1956). Para Bar-Yam (1997), é da base construída pela teoria geral dos sistemas que a teoria de SAC's deve partir.

Até quanto se sabe, a idéia de uma teoria geral de sistemas foi introduzida nos anos 1930 pelo biólogo austríaco Ludwig von Bertalanffy. A primeira apresentação oral do conceito foi feita por Bertalanffy em Chicago, em 1937, e as primeiras apresentações em artigos se deram entre 1945 e 1950 (KLIR, 1969). Bertalanffy seguiu uma linha de pensamento trilhada por outros cientistas e filósofos que, desde Aristóteles, com a teleologia, e passando por Leibnitz e Kant, procuraram uma filosofia natural: um conjunto de explicações que descreva, com poucas adaptações, qualquer observação na natureza. As obras de Lotka e de Whitehead, de 1925, e de Cannon, de 1929, entre outras, prenunciaram e subsidiaram tais idéias (SELLITTO, 2005a).

Não é provável que venha a surgir uma definição unificada para o termo sistema: Klir (1969) reuniu vinte e quatro definições diferentes para o termo. Bertalanffy $(1976 ; 1977)$ elaborou seu conceito de sistema ao perceber que idéias gerais referentes a todos organizados poderiam ser aplicadas a outros todos organizados. Para ele, um sistema é um complexo de elementos que operam relações ordenadas, não fortuitas. Elementos p participam em relações $R$, de modo que o comportamento de $p_{1}$ em $R_{1}$ é diferente do comportamento de $p_{1}$ em $R_{1}$. Se os comportamentos de pi em $R_{i}$ não forem diferentes, não há interação mútua e as relações $R_{i}$ independem dos elementos $p_{i}$. Hopeman (1977) classifica as relações em sistemas como: (i) de primeira ordem, se são vitais para o propósito do sistema, tal como o abastecimento de material em máquinas; (ii) de segunda ordem, se melhoram o desempenho de um elemento, tal como o treinamento do operador da máquina; e (iii) de terceira ordem, se aumentam a confiabilidade, tais como duas máquinas que podem cumprir a mesma tarefa. Para Checkland e Scholes (1999), um sistema é um todo complexo, cujas propriedades se referem ao todo e não às partes. Tais propriedades são: (i) emergentes, quando surgem do fato de diversas partes terem sido colocadas juntas no todo, tal como a capacidade de deslocamento que surge quando partes de uma bicicleta são agregadas; (ii) hierárquicas, se, a medida que se avança da base para o topo, varie seu alcance; e (iii) ligadas a sobrevivência, pois um todo só sobrevive em um meio variável se puder se auto-adaptar. Os autores propõem uma metáfora: um sistema é um conjunto adaptativo capaz de sobreviver em um ambiente mutável. Para Agostinho (2003), a propriedade básica de sistemas adaptativos complexos é a capacidade de modificar seu comportamento a partir do que consegue perceber sobre o meio e sobre seu próprio desempenho em atingir um propósito. Segundo a autora, os padrões de comportamento observáveis não são dirigidos externamente, mas emergem da interação entre agentes autônomos internos. Para Maciel (1974), um sistema é um todo organizado dinamicamente relacionado com o seu exterior, sujeito a mudanças permanentes e que apresenta a cada momento um modo diverso de ação ou comportamento. $\mathrm{O}$ autor destaca definições auxiliares: (i) transformada: é o novo estado de um sistema; (ii) transição: é a passagem de um estado a outro; (iii) transformação: é uma seqüência de transições; (iv) processo: é uma seqüência de transformações; ( $v$ ) desenvolvimento: é uma seqüência de todos os processos; e (vi) evolução: é a seqüência de desenvolvimentos. Segundo Bauer (1999), um sistema tem um sentido ou propósito, é orgânico, tem partes interdependentes e reage a estímulos externos, mesmo se estes forem aplicados a apenas uma ou poucas partes.

Sistemas podem ser abertos ou fechados. Os abertos realizam trocas, enquanto que os fechados são impermeáveis ao ambiente. Estes, pela segunda lei da termodinâmica, eventualmente chegam a um estado de equilíbrio em que os processos param. Aqueles podem alcançar um estado constante e independente do tempo, um equilíbrio dinâ- 
mico, em que os processos internos se mantêm ativos e sustentados por trocas com o ambiente. Um sistema está em repouso antes do instante inicial, a ativação, e após o instante final, a desativação. Entre estes instantes, processa entradas e gera saídas, em um equilíbrio que só será rompido se um limiar for ultrapassado. Neste caso, o sistema sai de controle e a saída só será contida por barreiras físicas. Na busca do equilíbrio, devido a inércias intrínsecas, a variação na resposta não é instantânea, podendo ocorrer aproximações exponenciais, ultrapassagens (overshoots) e oscilações amortecidas. Pela propriedade da eqüifinalidade, dentro de certas faixas, pela autoregulação, um novo estado de equilíbrio é alcançado independentemente das condições iniciais e das perturbações sofridas (BERTALANFFY,1976; 1977; HOPEMAN, 1977).

Sistemas podem ser estudados por modelos matemáticos baseados em variáveis. Variáveis são objetos abstratos que tem um nome e podem ou não ter uma correspondência mensurável no mundo real, podendo assumir formas categóricas ou simbólicas. O estado de um sistema pode ser descrito pela situação das variáveis de estado, a informação necessária para completamente caracterizá-lo. A cada mudança possível nas variáveis de estado corresponde uma transição entre estados. A quantidade de informação usada para descrever o estado de um sistema é relacionada à quantidade de conjecturas que devem ser feitas para acessar o estado atual de um sistema, dados todos os estados possíveis. Modelos probabilísticos podem ser aplicados ao estudo das transições entre estados. Caso o objeto seja uma população de sistemas, tais como um parque de máquinas, no longo termo, distribuições de probabilidades tornam-se distribuições de freqüência, restabelecendo, de certo modo, a ordem. Parâmetros de modelos, tais como valores esperados e dispersões, podem constituir parâmetros estruturais importantes e independentes do conteúdo do sistema. Devese ter em mente, no entanto, as limitações da linguagem matemática. Sistemas de alta complexidade, tais como o cérebro humano, ainda desafiam toda tentativa de modelagem(KLIR, 1991; RAPOPORT, 1976).

Para Bar-Yam (1997), a teoria de SAC's deve explicar a emergência da complexidade a partir de comportamento simples e a emergência da simplicidade a partir de comportamento complexo. Gell-man (2000) fala em comportamento superficial complexo que surge de simplicidade interna profunda. Gleick (1990) fala em regras locais simples. Bar-Yam (1997) fala em blocos básicos simples com os quais pode-se engendrar o comportamento complexo. Agostinho (2003) exemplifica com uma revoada de aves ou um cardume de peixes, em que um padrão complexo de movimentação surge se cada membro obedecer uma regra simples: manter distância constante dos adjacentes. Outros exemplos são os autômatos celulares de Von Neumann, quadriculado de comportamento complexo que surge de uma regra local simples: uma célula pode ser branca ou negra e muda de cor se quatro ou mais das oito células adjacentes forem brancas (LEWIN, 1994).

Em SAC's, agentes individuais interagem localmente, sem necessidade de um planejador central, adquirindo propriedades coletivas, tais como vida ou propósito. Estas propriedades não surgiriam isoladamente e desaparecerão se houver separação (GLEISER, 2002). Cadeias de suprimentos são exemplos de SAC. Basta que cada membro persiga prazos e quantidades requeridas pelo parceiro adjacente para formar um comportamento exterior difícil de decifrar a olho nu. Redes de cooperação também formam padrões complexos a partir de regras locais simples: se cada membro cumprir os requisitos impostos pelo meio e por outros membros, surge um padrão operacional complexo. No sentido contrário, sistemas adaptativos de alta complexidade interna podem produzir alguns poucos padrões de comportamento externo, os atratores (GLEICK, 1990). Em larga escala, um sistema de fabricação de automóveis, por exemplo, parece simples e previsível: entram matérias-primas, informações e energia, saem veículos. Reduzindo-se a escala da observação, surge o comportamento complexo: inúmeras alternativas de relacionamento entre partes que, observados de longe, podiam ser considerados inexistentes ou irrelevantes. Por exemplo, a relação entre a qualidade observada no produto e os movimentos de um equipamento robotizado; o estoque em processo e as heurísticas de programação de produção; o comportamento dinâmico dos membros de uma cadeia de suprimentos, a previsão de demanda e a informação sobre estoques.

Agostinho (2003) resume e sintetiza: sistemas complexos adaptativos são organizações de agentes autônomos e ativos, cuja ação é governada por regras de comportamento sujeitas a modificações e aprendizado por pressões do ambiente, informações de desempenho e pela própria situação do ambiente. O comportamento global do sistema emerge, então, como efeito da combinação de interações não-lineares entre agentes ativos e componentes observáveis do sistema.

A complexidade em SAC's surge como fluxos de informação em que há regularidades observadas e também aleatoriedades. As regularidades são comprimidas em um schema, um modelo para descrever o sistema, prever seu comportamento e reorganizá-lo. O schema oferece alternativas que competem pela primazia de adaptar o sistema para sobrevivência e evolução, segundo as pressões seletivas do meio. Eventualmente, o modelo também evolui se novas e diferentes informações e pressões por adaptação, exigidas pelo meio, chegarem ao sistema (LEWIN, 1994; GELL-MANN, 2000).

Sistemas podem ser classificados segundo a complexidade. Um continuum conteria, em uma extremidade, siste- 
mas muito simples e pouco adaptáveis, caracterizados por um pequeno número de elementos, com interações fracas, governados por leis claras e delimitadas, fechados ao ambiente e estáticos no tempo. Este tipo de sistema seria pouco suscetível a influências e seus subsistemas não teriam objetivos específicos. A outra extremidade do continuum conteria sistemas muito complexos, com muitos elementos e fortes interações mútuas. Tais sistemas seriam probabilísticos, abertos e dependentes do ambiente, evoluem e se diferenciam no tempo, e seus subsistemas possuem objetivos próprios. Sistemas planetários estariam na primeira extremidade, enquanto que grupos humanos estariam na segunda. Sistemas de fabricação ou prestação de serviço estariam em posições intermediárias, segundo seu mecanicismo ou organicismo (SELLITTO, 2005a). Quando o objetivo de produção inclui alta padronização, redução de custo por aumento de escala e baixa diversidade no composto de produção, algum mecanicismo pode ser observado, mas, ainda assim, em escala menor do que o é em sistemas planetários. Fabricação de matérias-primas em larga escala é um exemplo. Quando o sistema inclui objetivos de diferenciação, alta diversidade, volatilidade em recursos, alta diversidade no composto de produção e a participação de múltiplas entidades no processo produtivo, mais organicismo é observado, porém menos do que em relações humanas complexas, São exemplos: produção de moda, de alta tecnologia e prestação de serviços diferenciados, tais como projeto de máquinas e assistência técnica.

\subsection{Auto-organização e variedade em sistemas adaptativos complexos}

Para Rapoport (1976), quanto mais estreitas as relações entre as partes, mais bem equipado e mais auto-organizado o sistema é para reagir às perturbações. A auto-organização de um sistema é centrada nas noções de intencionalidade e adaptação. Para Sterman (2000), é pela auto-organização que um sistema compatibiliza estrutura interna e propósito. Para Bertalanffy (1977), são características da auto-organização as noções de crescimento, diferenciação, hierarquia, controle, dominância e competição. É possível mensurar tais noções por modelos quantitativos. A noção de crescimento, por exemplo, pode ser modelada pela lei de crescimento exponencial positivo, na qual a taxa de variação é proporcional ao tamanho do sistema, ou pela curva logística, que limita o crescimento. Quando só se pode chegar a um modelo verbal, usam-se modelos qualitativos.

Gouldner (s.d., apud THOMPSON, 1976) descreve a autoorganização segundo os modelos racional e natural. O modelo racional é deliberado para alcançar um objetivo explícito, tal como em uma manufatura, ou implícito, tal como em escolas e hospitais. As partes e a estrutura são escolhidas segundo sua capacidade de contribuição para o atingimento dos objetivos e as ações de controle são previstas segundo relações de causalidade presumidas. Já para o modelo natural, a organização é um todo formado por partes interdependentes que contribuem para o objetivo do todo e recebem uma retribuição do ambiente. O modelo natural estabiliza as relações entre as partes, reagindo às perturbações do ambiente e mantendo o equilíbrio funcional. Um sistema natural não é racional nem previsível, mas adapta-se espontaneamente aos desvios. Entende-se que organizações que sigam modelos explícitos, tais como a administração científica ou o modelo da burocracia, são concebidas mais como modelos racionais. Já organizações de adesão voluntária, tais como clubes e associações culturais, parecem ser concebidas mais como sistemas naturais.

Ashby (1956, apud JACKSON, 1993) define variedade como o número de estados que um sistema pode assumir, podendo ser uma medida de sua complexidade. Este número depende da capacidade do observador em discernir entre estados observáveis. Para o autor, o controle de um sistema em ambiente probabilístico deve ter maior variedade do que o ambiente. Por exemplo, se uma manufatura pode interromper a produção por vinte modos de falha, o sistema de controle deve poder reparar, ao menos, estas vinte falhas.

Algumas estratégias para atender a requisitos de variedade são possíveis (BEER, 1984, apud JACKSON, 1993): (i) reduzir a influência da variedade ambiental padronizando atividades; (ii) aumentar a variedade do sistema por aprendizagem, novos recursos e diferenciação; e (iii) combinar as alternativas. Para que haja variedade, deve antes haver redundância, ou seja, duas ou mais partes devem poder cumprir as mesmas tarefas. Se, por aprendizagem ou evolução, uma delas capacita-se para uma nova tarefa, aumenta a variedade e a complexidade. Se a parte que evoluiu deixa de ser capaz de cumprir a tarefa original, trocase variedade por redundância ou confiabilidade. Se pode cumprir ambas, agrega-se variedade e complexidade sem perda de redundância ou confiabilidade.

Observa-se que uma organização de trabalho tem ordem e previsibilidade, surgidas da repetição, regularidade e redundância; e desordem, surgida da inovação e da incerteza no ambiente (BAUER, 1999). Morin (1990) considera que a complexidade em tais organizações promove a ineficiência gerencial, mas é fonte de vitalidade, pois permite que indivíduos e grupos diferentes promovam emergências, que resultam em aprendizado, renovação, capacidade de adaptação e inovação.

No método utilizado na linha de pesquisa já mencionada, o conceito de auto-organização surge no modo como as interações entre as partes são elaboradas, explicadas e como as intensidades das relações entre as partes são avaliadas. 


\subsection{Quantidade de informação em sistemas complexos adaptativos}

Já foi mencionado que a complexidade presente em um SAC pode ser associada à quantidade de informação necessária para descrevê-lo. Atlan (1992) propôs a transposição do conceito de informação contida em uma mensagem para informação contida em um SAC. O autor propôs que um observador mensure um conjunto de variáveis de estado e o trate como uma mensagem. A teoria da informação quantifica a informação contida na mensagem e pode ser usada para quantificar a complexidade em um SAC.

Seja uma seqüência de caracteres $\mathbf{s}=\left[s_{1}, s_{2}, \ldots, s_{n}\right]$. A informação contida no caracter diz respeito ao que ele é e ao que não é. Se foi recebido um 0 e o alfabeto é binário, o caracter não é 1 . Se o alfabeto é hexadecimal, o caracter recebido não é 1,2 ,..., F. Ou seja, há mais informação em um caracter que pode assumir dezesseis estados do que em um que pode assumir dois. A quantidade de informação não depende do caracter recebido, pois nada mudaria se este fosse 1. A informação reside na distinção entre o estado recebido e os demais estados possíveis e a quantidade de informação é inversamente proporcional à quantidade de incerteza contida na mensagem. Para quantificar a informação contida em um objeto, é preciso quantificar o número de possíveis estados que este pode assumir. A quantidade de informação é dada pela equação 1, na qual, $Z$ é o número de estados possíveis e I(s) é a informação contida no objeto (BAR-YAM, 1997).

$I(s)=\log _{2}(Z)$

Alfabetos binários são convenientes, pois a informação contida em um bit (dois estados possíveis) é $\log _{2}(2)=1$. A informação contida em uma seqüência de $n$ bits ( $2^{n}$ estados) é $\log _{2}\left(2^{n}\right)=n$, ou seja, cada bit provê uma unidade de informação. A informação cresce linearmente e o número de estados cresce exponencialmente com o tamanho da seqüência.

É possível associar probabilidades aos recebimentos. Por exemplo, sejam dez eventos de igual probabilidade, nove associados a 0 e um associado a 1 . Se o bit recebido for 1 , a informação descarta nove eventos, se for 0 descarta um evento. No caso geral, a seqüência recebida é uma entre muitas possíveis e a informação é dada pela equação 2, na qual P(s) é a probabilidade da seqüência ser recebida. Se a distribuição de probabilidade for uniforme, $P(s)=1 / Z$ e a equação 2 recai na equação 1 (BAR-YAM, 1997; BAUER, 1998).

$I(s)=-\log _{2}[P(s)]$
Generalizando, a probabilidade de recebimento de $\mathrm{n}$ caracteres independentes em seqüência é o produto das probabilidades de cada caracter (equação 3). O conteúdo de informação da seqüência é dado pela equação 4. Se houver $k$ caracteres no alfabeto e as probabilidades forem uniformes, o conteúdo de informação da seqüência recebida é dado pela equação 5.

$$
\begin{gathered}
P(s) @ \underset{i @ 1}{{ }_{i \circledast 1}^{n}} P\left(s_{i}\right) \\
I(s) @ 0 \hat{\mathrm{I}}_{i \circledast 1}^{n} \log \hat{P}\left(s_{i}\right)^{\prime} \\
I(s) @ n \log (k)
\end{gathered}
$$

A informação contida em uma seqüência de caracteres depende da probabilidade de recebimento da seqüência, entre todas as seqüências possíveis. Caso se deseje caracterizar não a seqüência, mas a fonte, deve-se buscar não o conteúdo da seqüência específica, mas o conteúdo médio de informação em todas as seqüências possíveis. A informação média de uma mensagem é a quantidade de acaso nela contida. Para $p$ possíveis seqüências, com uma distribuição de probabilidade $P(s)$, o conteúdo médio de informação é dado pela equação

$\bar{\theta} @ 0 \hat{I}_{i @ 1}^{p} P\left(s_{i}\right) \cdot \log \left[P\left(s_{i}\right)\right]$

Uma seqüência de símbolos pode ser associada a um vetor de variáveis de estado representativo de um SAC. O conteúdo de informação médio deste vetor é uma medida da complexidade do sistema. Uma simplificação assumida e que não será flexibilizada é a independência entre símbolos. Caso haja correlação entre variáveis de estado, o cálculo do conteúdo de informação médio deve considerar probabilidades conjuntas $P\left(s_{i}, s_{j}\right)$.

Se a seqüência recebida é $\left[s_{1}, s_{2}, \ldots, s_{n}\right]$ e cada caracter si tem uma probabilidade $P\left(s_{i}\right)$, o conteúdo médio de informação é dado pela equação 7 . O somatório interno computa o conteúdo informacional de cada caracter, enquanto que o somatório externo integra este valor ao longo de toda a seqüência. O conteúdo médio de informação em uma seqüência é a informação média contida em cada caracter; somada ao longo da seqüência. Se as probabilidades de incidências de caracteres forem uniformes, o conteúdo médio de informação da seqüência é a média de informação em um caracter, vezes o número de caracteres, recaindo na equação 5 (BAR-YAM, 1997).

$$
\bar{I} @ 0 \text { @ } \hat{I}_{i \oplus 1}^{p} \hat{I}_{j @ 1}^{n} P\left(s_{j}\right) \cdot \log \left[P\left(s_{j}\right)\right]
$$


Os modelos usados para descrever o sistema podem ser diretos, quando o conteúdo da informação é expresso diretamente pelos símbolos recebidos, ou computáveis, quando é preciso processá-los. Por exemplo, se a seqüência a transmitir são os $n$ primeiros números primos, basta informar n e o algoritmo gerador (BAR-YAM, 1997). Processamento de símbolos é estudado na teoria da computação e não interessa para este artigo.

No método que foi usado na linha de pesquisa já mencionada, a complexidade de arranjos produtivos é calculada pelo formulário apresentado.

\section{Sistemas dinâmicos e realimentação}

Um sistema dinâmico é um conjunto de fenômenos relacionados entre si e que evoluem no tempo. Sistemas dinâmicos podem ser lineares ou não-lineares. Nos primeiros, as respostas variam na mesma proporção em que variam os estímulos, tal como na mecânica dos sólidos newtoniana. Nos segundos, não há esta proporcionalidade: pequenos distúrbios podem causar grandes alterações ou grandes distúrbios podem não alterar a resposta. Duas características podem estar presentes em sistemas dinâmicos não-lineares: realimentação e níveis críticos. Pela realimentação, partes das saídas retornam às entradas e afetam o comportamento futuro do sistema. Matematicamente, os resultados atuais das equações que descrevem o sistema são variáveis de entrada para a próxima iteração, em recursividade. Pelos níveis críticos, o sistema tem um comportamento abaixo de um certo patamar de algumas variáveis e outro comportamento, totalmente diferente, acima deste patamar, tal como ocorre em avalanches: um pequeno deslocamento adicional gera grande liberação de energia, até então inativa (GLEISER, 2002).

A descrição de uma dinâmica de sistema pode ser por um conjunto de variáveis que descrevem os estados do sistema e uma regra de evolução destas variáveis. Na evolução mais simples, o sistema converge para um valor fixo: atingido este valor, o estado do sistema torna-se independente do tempo. A seguir vêm as evoluções não-estacionárias, que visitam periodicamente estados, em oscilação de freqüência fixa ou soma de oscilações de várias freqüências. Por fim, vem o estado caótico, composto por turbulências que podem ser descritas como uma integração de infinitas freqüências contínuas. Sistemas dinâmicos complexos são centrados na realimentação e em processos iterativos, ou seja, o estado atual é conseqüência do estado anterior. A iteratividade é importante fonte de comportamento complexo. Sistemas iterativos com objetivos fixos usam a realimentação negativa, enquanto que sistemas com objetivos de crescimento auto-sustentado, reações em cadeia ou auto-reforço usam a realimentação positiva (PEAK e FRAME, 1994).

\subsection{Realimentação negativa: a cibernética}

Em sistemas de objetivos fixos, deve-se considerar a autoregulação por realimentação negativa como esquema de controle para atingir e manter a estabilidade. A Figura 1 representa a forma canônica do controle por malha de realimentação negativa, a malha cibernética.

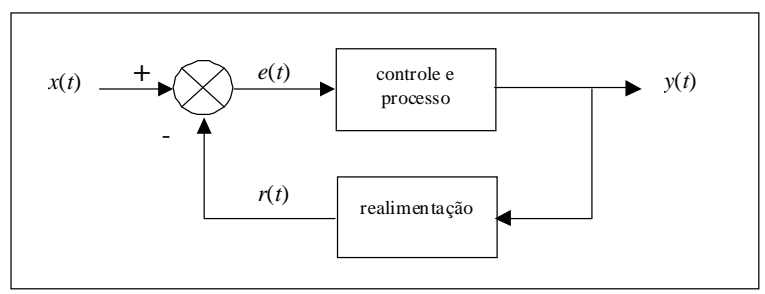

Figura 1: Esquema canônico da auto-regulação por realimentação negativa

Uma malha de realimentação negativa tem um bloco de ações de controle na linha direta, um bloco de informação na linha reversa e um bloco de comparação entre objetivo e informação: (i) um objetivo $x(t)$, gerado fora do sistema; (ii) um sensor $r(t)$ que informa sobre o estado atual da saída $y(t)$; (iii) um comparador que compara esta informação com o objetivo e gera o erro e(t); e (iv) um controlador que retira energia do ambiente para responder ao erro com ações que o reduzam. Na figura, é possível verificar que $y(t)$ é causada por $x(t)$ e $r(t)$ e que $r(t)$ é causada por $y(t)$. Sendo assim, $y(t)$ é em parte causa de si mesmo (LHOTE; CHAZELET; DULMET, 1999).

A noção de realimentação negativa explica comportamentos cuja motivação é atingir uma meta. A informação sobre a diferença entre as situações atual e desejada é autoorganizante, pois é usada pelo governador do sistema para mobilizar e ativar os recursos que reduzirão os efeitos indesejáveis da desestabilização e da deterioração das partes. Retardos devem ser considerados, pois correção excessiva ou antecipada pode fazer a saída oscilar. O esquema também é referenciado como auto-regulação cibernética.

Morin (1990) credita a entrada da complexidade na cena científica a Wiener e Ashby, fundadores da cibernética, e a Von Neumann, que a relatou na fenomenologia da autoorganização. Nos anos 1940, Norbert Wiener propôs uma ciência que deveria compreender os fenômenos naturais e artificiais através do estudo dos processos de comunicação e controle. A cibernética foi concebida como uma ciência interdisciplinar, tratando por leis generalistas todo problema de controle. A cibernética explica o funcionamento de fenômenos por um mecanismo de governo, um objeto a governar e um elo de realimentação, que informa ao mecanismo de governo o resultado das suas decisões. Segundo as idéias centrais da cibernética, um sistema 
deve: (i) perseguir um objetivo; (ii) receber continuamente informações acerca do seu próprio comportamento em relação ao objetivo; e (iii) ter governo sobre seu próprio comportamento (JACKSON, 1993; ANOHIN, 1976).

Nos anos 1940, membros do grupo de fundadores da cibernética, insatisfeitos com a dicotomia entre as ciências hard, como a física, e as ciências soft, como a psicologia, propuseram uma abordagem interdisciplinar, cuja idéia central surge da analogia matemática observada entre sistemas naturais e sistemas artificiais. A abordagem estendia a testagem empírica das ciências naturais a um novo ambiente, distante dos processos energéticos e materiais, a simulação. Na base do novo método encontra-se uma epistemologia construtivista, que dialoga com a natureza através de construções teóricas criadas de modo liberal pela mente humana, mas que garantem uma conexão entre a teoria e o experimento, os modelos (LICATA, 2004).

Na Figura 2, representa-se o método proposto pelo grupo. Dada uma situação complexa, surge uma representação simbólica do problema, apoiada nas chamadas variáveis proxi. Admitidas premissas simplificadoras, necessárias perante a racionalidade limitada dos modeladores, poucas variáveis passam a aglutinar os múltiplos aspectos da situação. O simbolismo representa como o pesquisador vê a situação complexa, podendo variar segundo crenças e teorias, ou seja, uma coisa é o sistema real, outra coisa é como o pesquisador o vê. Realizados os testes no mundo simbólico, usam-se os resultados, à luz da teoria, para decidir no mundo real e modificar a situação originalmente observada. O esforço despendido para a modelagem da situação complexa contribui para o entendimento, pois se explicitam os elementos internos, as interações e relações com o ambiente e os resultados esperados do modelo (SELLITTO, 2005a).

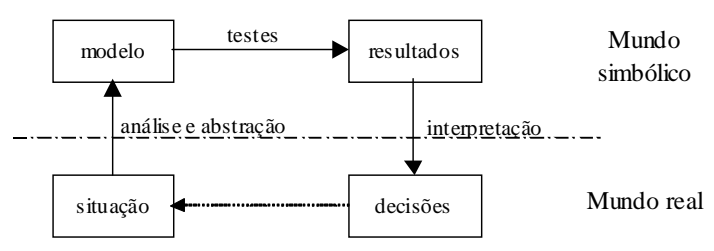

Figura 2: Modelos como representação de situações de interesse (fonte: Sellitto, 2005a)

Bertalanffy (1976) aponta uma diferença entre a cibernética canônica e a teoria geral dos sistemas adaptativos complexos: enquanto aquela trata de mecanismos de realimentação monovariável e unidirecional, estes regulam-se por interações multivariáveis e múltiplos modos de controle. As regulações cibernéticas ocorrem segundo estruturas fixas e conhecidas, abertas em relação à informação e fechadas em relação à energia e à matéria, ao passo que as regulações sistêmicas ocorrem segundo interações dinâmicas. A regulação cibernética conduz a um estado homeostático, de equilíbrio no tempo, sendo um princípio sincrônico. Já a regulação multivariável é um princípio desenvolvimentista diacrônico, pois conduz a resposta de um sistema em uma trajetória evolutiva de organização e diferenciação. Clemson (1984, apud JACKSON, 1993) diferencia uma cibernética de primeira ordem, material e energética, de uma cibernética de segunda ordem, que trata de subjetividades e ambigüidades, tais como as encontradas em relações humanas. É esta noção que permitiu a entrada da cibernética nas ciências do gerenciamento de organizações. Um modo de usar este tipo de conhecimento na gestão nestas ciências é via dinâmica de sistemas.

\subsection{Realimentação positiva: o caos}

Ao contrário da realimentação negativa, que produz estabilidade, a realimentação positiva produz desequilíbrio. A entrada é somada à saída, o erro cresce e com este cresce o desequilíbrio, criando sinergias e podendo levar ao comportamento caótico.

O caos admite dois tipos de comportamento: instável e aperiódico. O comportamento instável surge quando uma pequena alteração nas condições iniciais do sistema ou de seu conjunto de equações provoca uma mudança irreversível na saída, desequilibrando permanentemente o sistema. O comportamento aperiódico ocorre quando os valores das variáveis de estado nunca se repetem. Os dois comportamentos podem ocorrem simultaneamente. Neste caso, as saídas do sistema não se repetem e o sistema salta permanentemente entre estados de desequilíbrio. Previsões confiáveis sobre o próximo estado são improváveis(GLEISER, 2002).

A teoria do caos foi inicialmente proposta pelo meteorologista Edward Lorenz, que, em previsões climáticas, observou que o comportamento final apresentava sensibilidade às condições iniciais: pequenas variações nestas produziam grandes e improváveis variações naquele. Ao simular em computador um sistema de doze equações com variáveis interdependentes, ao invés de digitar como condição inicial 0,506127, Lorenz digitou 0,506 . Em uma hora de recursividade, o sistema inicialmente manteve-se muito próximo da trajetória inicial, mas após migrou por um caminho de soluções radicalmente diferente, formando uma nova série de dados. A única diferença foi a retirada dos três últimos dígitos, o que estabeleceu um novo modo de pensar científico: diferenças ínfimas na entrada promoveram grandes diferenças na saída. Lorenz parafraseou o fenômeno comparando-o a um eventual bater de asas de uma borboleta, que causa mínimas alterações climáticas locais, mas que, amplificadas e realimentadas, poderiam causar um furacão alhures (GLEISER, 2002). 
Lorenz abandonou a busca do equilíbrio dinâmico da realimentação negativa e adotou a dinâmica não-linear da realimentação positiva como pressuposto de investigação. Segundo o posterior desenvolvimento da teoria, há determinismo e incerteza simultâneos nos sistemas caóticos. Iguais perturbações levam dois sistemas idênticos ao mesmo estado final, mas este será imprevisível caso haja uma ínfima variação nas condições iniciais ou nos parâmetros do sistema. Sistemas caóticos apresentam um limite, a fronteira do caos: aquém, o comportamento é ordenado; além, é imprevisível. É difícil, nesta área de fronteira, discernir entre a estabilidade e a instabilidade, porque são muito próximas as condições iniciais que levam a um ou outro caso, surgindo um terceiro tipo de comportamento, a instabilidade circunscrita. Feingenbaum demonstrou que diversos tipos de sistemas caóticos naturais seguem um mesmo padrão de comportamento, independente das partes que o compõem, intercalando ciclos ordenados e aparente desordem, e mantendo relações quantitativas constantes entre os pontos em que ocorrem as bifurcações, as mudanças qualitativas de comportamento. É nesta área de fronteira ou de instabilidade circunscrita que nasce o comportamento complexo (GLEICK, 1990; PARKER STTACEY, 1995).

Situações caóticas são geradas por realimentação positiva, o que conduz o sistema a pontos de inflexão e ruptura, os pontos de bifurcação. É a partir destes pontos que ocorre dissipação de energia e informação, do que resulta descontinuidade e reorganização. O comportamento caótico se difere do comportamento aleatório, embora ambos sejam desordenados. Não há, na aleatoriedade, uma lei que explique o comportamento do sistema, atribuindo-se este a infinitas causas que, somadas, produzem a desordem. Já no caos existem leis não-lineares iterativas, funções de si mesmo, leis determinísticas de ordem que produzem e explicam a desordem. Pode se dar que estas leis não se mostrem imediatamente e superem a habilidade de um observador humano em entendê-la e usá-la para prever o comportamento futuro. O termo caos encerra uma aparente contradição: em relação ao determinismo, caos é desordem, pois o estado de um sistema é imprevisível; em relação ao acaso, é ordem, pois o estado imprevisível surge de uma lei anterior, descrita por um sistema de equações, o atrator (ROCHA NETO, 2003; BAR-YAM, 1997; BAUER, 1998; PEAK e FRAME, 1994).

Na região de fronteira entre a estabilidade e a instabilidade, o comportamento do sistema é tão sensivelmente dependente das condições iniciais que as relações de causa-efeito se desfazem. Não é mais possível garantir que uma dada entrada continue levando a uma dada saída e o resultado pode passar de fixo a oscilatório ou caótico e vice-versa segundo uma mínima incerteza de entrada, às vezes indetectável por medição, ou uma mudança em parâmetro que, de tão pouco relevante em condições normais, nem conste no modelo do sistema. O comportamento observado pode se tornar indecifrável (PARKER e
STACEY, 1995). Uma observação de Poincarè sobre incertezaedeterminismoéessencia (apud RUELLE, 1993) "Uma causa muito pequena, que nos escapa, determina um efeito considerável que não podemos deixar de ver, e então dizemos que este efeito se deve ao acaso".

O conjunto das saídas de um sistema caótico é dito espaço de fase, um espaço multidimensional definido pelas variáveis de estado do sistema. Sistemas de comportamento caótico perseguem atratores, estados preferenciais de saída que atraem a evolução do sistema.

Um atrator é o conjunto sobre o qual se move o ponto multidimensional que informa o estado de um sistema dinâmico determinista, cessados os efeitos transitórios (RUELLE, 1993). Atratores podem ser fixos, quando o sistema converge para um único ponto; cíclicos, quando o sistema oscila entre $2^{k}$ estados $[k=0,1,2$,..]; ou estranhos, quando o sistema não repete seu comportamento, mas este é restrito a regiões delimitadas no espaço de fase. Atratores estranhos não são curvas ou superfícies sólidas, mas objetos de dimensão fracionária, os fractais. A fronteira do caos ocorre quando o atrator passa de cíclico a estranho. O caos é uma evolução temporal com dependência hiper-sensível das condições iniciais, que ocorre ao longo de um atrator estranho. A causa para o comportamento caótico não é externa nem devida a ruídos aleatórios, mas determinada pela estrutura própria não-linear do sistema. Ações de campos de força internos vão se alternando, segundo variam parâmetros ou condições iniciais de variáveis, conduzindo o sistema para um ou outro atrator. Por ser não-linear, o sistema pode assumir a mesma saída, mesmo quando submetido a várias entradas.

Kaufmann fez experimentos em redes boleanas com número variável de conexões, nos quais impunha condições iniciais e media as saídas binárias. O experimentador relata que, quando o número médio de conexões por nó era baixo, a saída convergia para valores únicos. Quando este número subia, mesmo havendo uma lei anterior conhecida, a saída era imprevisível. Para situações intermediárias, a saída era cíclica, aumentando o número de ciclos conforme aumentava o número de conexões por nó, o limiar do caos (LEWIN, 1994).

Um modelo caótico útil é o mapa logístico, um processo positivamente realimentado por uma função quadrática de si mesma, $\mathrm{x}_{(t+1)}=a x_{t}\left(1-x_{t}\right), 4>a>0$. Para a $<3$, o processo converge para um valor fixo. Se $a<1$, este valor é zero, se $1<a<3$, é $s=(a-1) / a$. O atrator é fixo. Para $3<$ $a<3,57$, o processo é cíclico, resultando bifurcações que conduzem a múltiplos valores. O atrator torna-se cíclico. Para $a>3,57$, o comportamento de saída torna-se caótico, podendo, para valores crescentes de $a$, eventualmente voltar ao comportamento cíclico. Agora, o atrator é estranho. Atratores fixos e periódicos correspondem aos resultados atingidos pela mecânica newtoniana. Atratores 
estranhos representam dinâmicas não-lineares, incorporando a asincronicidade e a interatividade entre as variáveis intervenientes no atrator (BAR-YAM, 1997; GLEISER, 2002).

O comportamento complexo ocorre próximo ao limiar de transição para atratores estranhos, a fronteira do caos. É nesta fronteira que surgem as condições para o complexo comportamento adaptativo de um sistema, pois há mais flexibilidade para adaptação às flutuações ambientais (HUTCHINSON, 1994; BAUER, 1998; PEAK e FRAME, 1994).

Variáveis encontradas em operações interorganizacionais, tais como séries temporais de demandas, podem apresentar comportamento caótico. Eventualmente, podem seguir trajetórias descritas por atratores, inclusive estranhos. Apenas a título de exemplo, apresenta-se um tipo de atrator estranho bastante conhecido, o atrator de Lorenz. $\mathrm{O}$ atrator é descrito pelo sistema de três equações (8), (9) e (10). Observa-se a interação entre as variáveis x, y e z, que comparecem, ora como saída, ora como entrada. Na Figura 3, observa-se o espaço de fase ocupado pelas variáveis $x$ ez.

$$
\begin{aligned}
& d x / d t=10(y-x) \\
& d y / d t=28 x-y-x z \\
& d z / d t=x y-2,67 z
\end{aligned}
$$

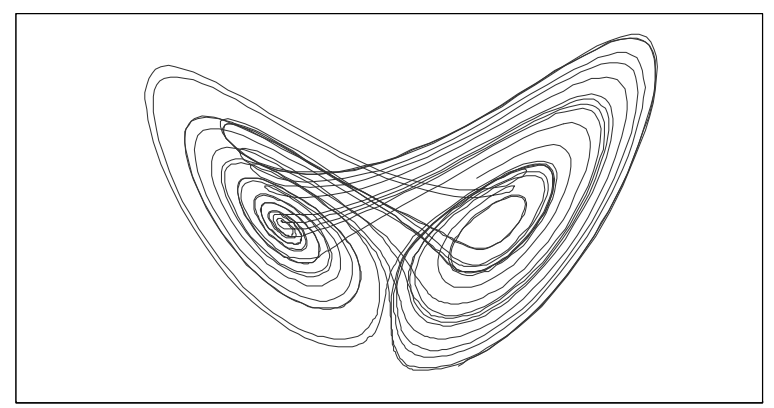

Figura 3: Atrator de Lorenz, espaço de fase x-z (Fonte: autores)

A noção de realimentação também é usada em modelagem qualitativa de comportamentos complexos. A Figura 4 apresenta um relacionamento realimentado entre dois entes em um SAC.

O agente Adecide baseado em informações sobre o resultado de uma ação, e é influenciado pela sua própria ação e pela ação de um agente $B$, que pode representar as interações de todos os outros agentes operando no mesmo ambiente. De modo recíproco, o agente $\mathrm{B}$, o ambiente, decide baseado no resultado de suas próprias ações e das ações do agente $A$, em comportamentos realimentados.
Realimentações surgem na representação da realidade complexa por instrumentos qualitativos de modelagem e representação de relações, tais como mapas cognitivos (ENSSLIN, MONTIBELLER e NORONHA, 2001), diagramas causais da dinâmica de sistemas (STERMAN, 2000; SENGE, 1990) e árvores de realidade atual, ARA, proposta pela Teoria das Restrições (SELLITTO, 2005). ARA's podem representar estruturas lineares, mas se prestam muito bem para a representação de estruturas realimentadas de alta complexidade. Exemplos de estrutura complexa realimentada modelada por ARA são apresentadas em Sellitto (2005) e em Sellitto, Ribeiro e Petrillo (2007). Ruelle (1993) alerta que, em ciências sociais, como o sistema aprende e evolui, eventuais equações mudam com o tempo e a percepção do comportamento caótico é mais qualitativa do que quantitativa.

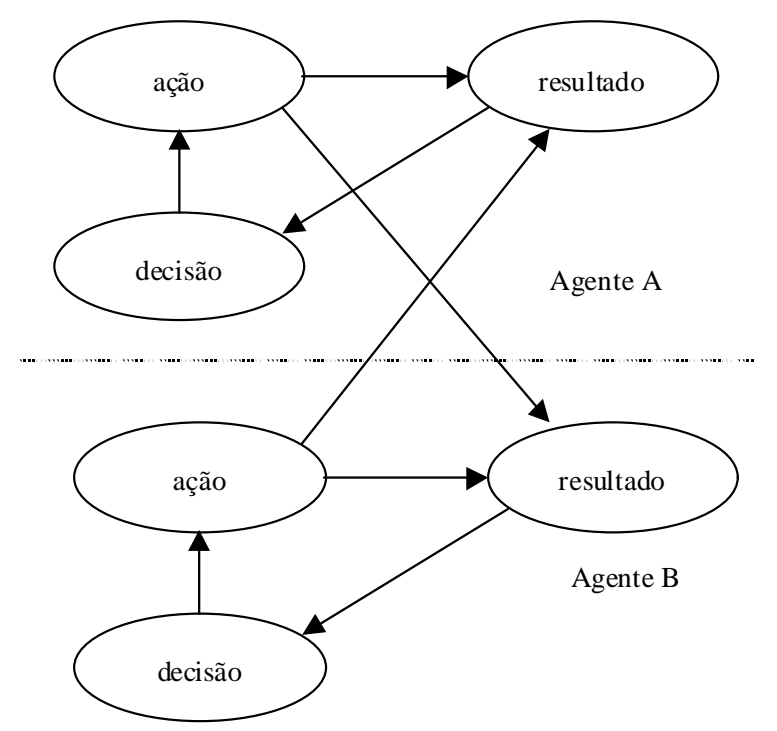

Figura 4: Diagrama de relacionamentos em sistemas realimentados (Fonte: Parker e Stacey, 1996)

\subsection{Autopoiese e estruturas dissipativas}

Autopoiese e estruturas dissipativas são conceitos originados, respectivamente, na biologia e na fisico-química, e podem ser úteis na descrição de comportamentos de sistemas complexos adaptativos em desequilíbrio, Nestes casos, ao menos uma variável de estado do sistema está consideravelmente afastada de sua posição esperada, o que gera tensões internas e estimula a auto-reorganização. A inteligência governante estuda as possibilidades e escolhe outra forma de organizar os recursos internos, reconfigurando o sistema para tratar ou se adaptar ao desequilíbrio.

Por exemplo, considere que numa manufatura, em um dado instante, não seja possível atender no prazo todos os pedidos já confirmados e aceitos. Avariável confiabilidade de entrega torna-se afastada da posição esperada e este desequilíbrio gera uma tensão interna. A inteligência 
governante tem alternativas para reequilibrar a manufatura: mais turnos de trabalho; mais máquinas; tornar o produto mais fabricável; ou informar a alguns clientes que não serão atendidos, abrindo mão de cumprir a missão. Cada alternativa tem pontos fortes e frágeis e a decisão geralmente é multicriterial. Algumas alternativas são reversíveis, tais como novos turnos de trabalho. Outras são parcialmente reversíveis, tais como mudanças no lay-out ou na estratégia de operação. Outras são de improvável reversão, tais como melhorias no projeto de produto ou a compra de mais máquinas. Nestes casos, a tensão interna causada pelo desequilíbrio é de tal monta que a autoreorganização pode produzir um novo sistema, diferente do original. A reorganização pode implicar uma nova linha de produtos e uma nova linha de clientes, o que pode ser considerado até um novo sistema de produção. O sistema então evoluirá de modo irreversível, devido a decisões tomadas nos pontos de bifurcação. Dadas as dificuldades de voltar atrás, por exemplo, recompondo máquinas que já foram desmontadas ou vendidas, uma eventual reversão seria de tal modo improvável que os resultados da decisão podem ser considerados quase irreversíveis.

Autopoiese (do grego poiein: produzir) é um termo que se refere à autoprodução, à ação de um sistema que produz a si mesmo, de modo auto-referenciado: a inteligência governante olha para o próprio sistema e adota a própria identidade como o referencial a ser mantido, apesar das modificações que venham a ocorrer no meio-ambiente. A inteligência reorganiza as partes e redistribui funções, em processos circulares de comunicação e controle. Em biologia, a autopoiese expressa a capacidade de seres vivos em produzir sua própria preservação e manutenção por processos controlados de trocas de energia e materiais com o ambiente (BAUER, 1998).

A noção de autopoiese surgiu na obra do filósofo setecentista Giovanni Battista Vico, mas é com os biólogos chilenos Maturana e Varella, em meados do século $\mathrm{XX}$, que o conceito encontra a sua forma atual. Maturana, em 1963, descobriu que o DNA participa da síntese das proteínas de células que, por sua vez, participam da síntese do DNA, em circularidade. A autopoiese é a característica de seres vivos de renovarem-se continuamente, por processos regulados, mantendo íntegra sua estrutura, autonomia e individualidade, apesar da incessante mudança no ambiente. A autopoiese exprime a capacidade de sistemas auto-organizados em manterem sua identidade, por mais que as suas partes constituintes sejam renovadas e modificadas, subordinando, por auto-organização, a relação com o ambiente à manutenção da identidade. Uma fábrica ou cadeia que produz peças de reposição e renova suas máquinas, é autopoiética. Sistemas autopoiéticos reagem a perturbações moderadas do ambiente, modificando variáveis que as neutralizem e mantenham qualitativamente inalterado o sistema. Autorenovação, automanutenção e autocriação são ter- mos encontrados na literatura para comunicar a noção de autopoiese (COATS, 1993; BAUER, 1998).

Na linguagem de Maturana e Varella (apudBAUER, 1998), um sistema é autopoiético se puder ser descrito como uma rede de produção de componentes em que as interações entre estes regeneram a rede que os produziu e se o sistema percebe a si próprio como unidade, reconhecendo uma fronteira que o separe do meio-ambiente. $\mathrm{O}$ sistema importa insumos e informação do meio-ambiente e exporta refugos e produtos.

Estruturas dissipativas foram propostas pelo químico Ilya Prigogine, em oposição às estruturas de equilíbrio até então adotadas, para explicar o comportamento de sistemas fisico-químicos, tais como soluções líquidas e colóides. Estes sistemas, quando submetidos a desequilíbrios expressivos, ao invés de recuperar o equilíbrio, reorganizam-se em novas formas qualitativas. Esta reestruturação ocorre após a ultrapassagem de um limiar de afastamento do equilíbrio termodinâmico, abaixo do qual o sistema tende a um estado de máxima entropia e mínima complexidade. Há, na reorganização, expressiva dissipação de energia captada do ambiente e usada na transformação interna do sistema. Uma manufatura que decide mudar seu equipamento e sua linha de produtos, e para tal precisa reestruturar o sistema de produção, retira energia de fontes externas e a dissipa na consecução de seu propósito. Os sistemas não-lineares captam energia do ambiente e a dissipam internamente, destruindo a estrutura anterior e permitindo a emergência de uma nova e inesperada estrutura(PARKER e STACEY, 1995).

Afastadas do ponto de equilíbrio, estruturas dissipativas fazem escolhas em pontos críticos da evolução, mudam sua estrutura qualitativa e percorrem trajetórias em bifurcações irreversíveis. Admitem a incerteza na mudança evolutiva, mas uma vez concluída a transformação, surge uma nova ordem, tal como expresso no título da obra de Prigogine, de 1984, Order out of chaos (COATS, 1993). O aumento na complexidade dos sistemas dissipativos ocorre pelo surgimento de interações não-lineares entre partes e correlações de longo alcance entre comportamentos (BAUER, 1998).

Estruturas dissipativas partem do desequilíbrio em direção a uma maior complexidade estrutural, assumem uma trajetória irreversível no tempo, importam energia do ambiente e a ele remetem seus resíduos. Tal comportamento joga um papel paradigmático no estudo de sistemas complexos adaptativos, haja vista que introduz a incerteza e a imprevisibilidade na evolução do sistema dinâmico. Sistemas dissipativos apresentam variedade em estados e correlações ou comunicações de longa distância entre as partes. Enquanto a autopoiese usa mais a realimentação negativa para manter a identidade do sistema, estruturas dissipativas valem-se mais da realimentação positiva para 
ampliar flutuações na relação com o ambiente e desordenar a estrutura existente. Após a destruição, a estrutura remanescente se auto-reorganiza e emerge uma estrutura totalmente nova e imprevisível, que pode ser irregular, fractal ou caótica.

Prigogine (1996) comenta: no determinismo newtoniano, a seta do tempo pode ser revertida, pois o comportamento passado pode ser calculado a partir do estado atual e da sucessão dos estados. Nestes sistemas, a desordem aumenta com o passar do tempo, pela segunda lei da termodinâmica. No entanto, o passar do tempo não desorganiza um sistema adaptativo, mas aumenta sua ordem, alcançando estruturas inéditas, mais complexas e mais coerentes. Este aumento de complexidade nasce do desequilíbrio extremo e produz trajetórias que não podem ser reconstruídas para trás, são irreversíveis no tempo. O desequilíbrio produziu conceitos, tais como a organização espontânea nos sistemas complexos adaptativos, quando partes são acrescidas ou retiradas, e as estruturas dissipativas, sistemas capazes de exportar entropia e assim aumentar sua complexidade.

A noção de dissipação é clara nos sistemas materiais e energéticos, mas deve ser adaptada a sistemas produtivos. Uma informação de desequilíbrio produz dissipação de recursos materiais e financeiros na busca do reequilíbrio ou de outra configuração. Na manufatura exemplificada, é do desequilíbrio em relação ao mercado que surge a tensão interna que a modifica, por exemplo, projetando novos produtos ou novas instalações. A dissipação de recursos que ocorre corresponde à dissipação energética nos sistemas fisico-químicos, materiais e energéticos.

Finaliza-se apontando a afirmação de Coats (1993): autopoiese e estruturas dissipativas são termos novos para idéias conhecidas. Porém, o autor também afirma que tais idéias, nascidas nas ciências naturais, são teorias de processo e podem ajudar a entender a dinâmica dos sistemas estudados em outros campos de conhecimento, tais como as ciências sociais, econômicas e administrativas.

As noções de autopoiese e estruturas dissipativas participam do método que suporta a linha de pesquisa já mencionada, pois podem ajudar a entender como evoluem as relações interna em cadeias de suprimentos e em redes de cooperação.

\section{Considerações finais e direções para pesquisa futura}

O objetivo deste artigo foi apresentar uma revisão necessária para a construção do marco teórico para a linha de pesquisa em andamento, já mencionada. Revisaram-se algumas das perspectivas sobre complexidade que surgem na literatura: linearidade e não-linearidade, teoria ge- ral dos sistemas, teoria dos sistemas complexos adaptativos, teoria da informação, dinâmica dos sistemas, cibernética, teoria do caos, autopoiese e estruturas dissipativas. Como o tema é multidisciplinar e tem recebido contribuições de diversos campos de conhecimento, entendeu-se útil reunir algumas delas em uma única fonte, formando a base para futura pesquisa em complexidade aplicada a operações produtivas interorganizacionais.

Um objetivo da pesquisa em andamento foi construir e testar um método para identificar os chamados pontos de alavancagem, aquelas ações sistêmicas que têm maior probabilidade de modificar, para mais ou para menos, a complexidade em operações interorganizacionais. Ações de alavancagem são aquelas ações exercidas em pontoschave do sistema e que, com maior efetividade, alcançam objetivos estratégicos. Estas ações podem objetivar tanto a redução como o aumento da complexidade, segundo a estratégia do arranjo interorganizacional (PERONA e MIRAGLIOTTA, 2004).

Alguns dos tipos de arranjos que podem ser estudados são cadeias de suprimentos, redes de cooperação, redes de inovação, filières agroindustriais, redes de distribuição de produtos e serviços de pós-venda ligados a fabricantes, redes de serviços e redes de franquias. Estes arranjos podem ser descritos sob o formato de sistemas adaptativos complexos, pois são compostos por partes, as empresas individuais, que se comportam segundo uma estratégia de arranjo e estabelecem entre si relações de mútua dependência e influência. Os resultados que surgem das interações e principalmente em resposta a estímulos externos, do mercado de negócios, podem levar o arranjo a estados inesperados, caracterizando o comportamento emergencial descrito na teoria dos SAC's (PERONAe MIRAGLIOTTA, 2004).

Em princípio, gestores de cadeias de suprimento talvez desejem reduzir a complexidade presente na operação quando sua estratégia for reduzir custo e aumentar eficiência. Neste caso, é necessário aumentar a escala de produção de cada parte, o que se consegue com a especialização, as chamadas fábricas focalizadas. Estas produzem grandes quantidades de poucos produtos, gerando partes muito diferentes entre si dentro da cadeia e que, em comparação com outros arranjos, precisam de menos troca de informação para funcionar. Pouca informação remete a complexidade reduzida. Se a estratégia de cadeia for de aumento de agilidade, é desejável que as mesmas tarefas possam ser realizadas em muitas partes, aumentando a probabilidade de que ao menos uma parte esteja ociosa e atenda imediatamente uma demanda. Neste caso, há pouca diferenciação entre as partes e uma tarefa pode ser executada em vários locais, o que exige mais coordenação, mais troca de informação e portanto mais complexidade. Tais afirmações se baseiam nos achados iniciais de pesquisa, já publicados em Sellitto, Borchardt e Pereira (2007). 
Raciocínios equivalentes podem ser propostos para redes. Se a rede é de cooperação, ou seja, uma tarefa deve ser dividida entre várias partes e cada parte fará o mesmo trabalho, o objetivo é reduzir a complexidade. Esta situação ocorre, por exemplo, em redes de malharias, quando um grande pedido de unidades iguais é produzido por diversas pequenas malharias. A comunicação entre partes é quase nula, pois cada uma delas só precisa se comunicar com uma parte concentradora, que fornece materiais e especificação e recebe produto acabado. Se o objetivo é dividir o esforço em uma teia, na qual muitos podem fazer muitas coisas, tal como ocorre em ateliers da indústria calçadista e de confecções, a necessidade de coordenação é maior, a troca de informação deverá ser maior e a complexidade deve ser aumentada, para que mais oportunidades de ganhos apareçam. O mesmo ocorre em redes de inovação, nas quais quanto mais talentos diferentes forem identificados, mais oportunidades de aprendizado e de surgimento de novas soluções para problemas novos ou velhos, Mais uma vez, é interesse do gestor que a complexidade presente no arranjo seja aumentada. Do mesmo modo, tais afirmações se baseiam nos achados iniciais de pesquisa, já publicados em Sellitto, Borchardt e Pereira (2008).

A idéia por trás da pesquisa é usar a noção de governança e controle que há na cibernética para modificar a complexidade presente no arranjo. Para estabelecer o elo de realimentação, em primeiro lugar, é necessário desenvolver um método para a medição da complexidade atual do arranjo. Como visto, esta medição requer medir a quantidade de informação presente no arranjo, o que pode ser obtido pelo formulário oferecido pela teoria da informação, Se for possível especificar as trocas de informações necessárias para a gestão do arranjo, será possível escrever um vetor de variáveis de estado que pode ser associado ao SAC. Tal vetor dá origem a um mapa que descreve as relações representativas para o objetivo do arranjo e apresenta as intensidades das relações em estudo. Aplicando o mencionado formulário, chega-se a uma mensuração da informação presente e por conseqüência da complexidade do arranjo. A mensuração poderá ser por medição quantitativa, obtida pela listagem das variáveis trocadas entre as partes, ou por avaliação quantitativa, por julgamento da força das interações existentes entre as partes.

Mensurada a complexidade, esta passa a ser a informação realimentada à governança do arranjo, que pode então decidir se aumenta, diminui ou mantém a complexidade. Se decidir não manter, a mensuração também deve informar quais as forças das interações entre todas as partes. Pelo mapa, o governante define em quais interações deverá atuar, aumentando ou diminuindo sua força e com isto controlando a complexidade presente na operação.
Nos próximos artigos, introduz-se e formaliza-se a noção da informação como elemento agregador da complexidade, que será usada como fundamento para sua mensuração nos sistemas complexos adaptativos interorganizacionais estudados.

Sintetizando, o grupo de pesquisa usou o marco conceitual ora apresentado para fazer as seguintes pesquisas de campo: avaliação qualitativa e controle da complexidade em uma cadeia de suprimento (já publicada) e uma rede de serviços de saúde (já aceita); análise comparada entre cadeias de suprimentos e redes de cooperação (em submissão); medição quantitativa e controle da complexidade em uma rede de cooperação entre ateliers generalistas da indústria calçadista e uma rede de fornecedores especializados da indústria metal-mecânica (em submissão); rede de empresas distribuidoras e prestadoras de serviços de pós-venda de um fabricante de produto de base tecnológica (em desenvolvimento); e rede de franquias de lojas ligadas a uma marca gerenciada por órgão centralizador (em submissão).

\section{Referências}

AGOSTINHO, M. Complexidade e organizações. S. Paulo: Atlas, 2003.

ALMEIDA, C. Sistema e auto-organização, In: Cirne-Lima, C. e Rohden, L (org.). Dialética e auto-organização. S. Leopoldo: Editora da Unisinos, 2003. (Coleção Idéias).

ANOHIN, P. Cibernética, neurofisiologia e psicologia. In: Anohin, P.; Bertalanffy, L. (org.). Teoria dos sistemas. R. Janeiro: Editora da Fundação Getúlio Vargas, 1976. (série Ciências Sociais).

ATLAN, H. Entre o cristal e a fumaça: ensaio sobre a organização do ser vivo. R. Janeiro: Jorge Zahar, 1992.

BAR-YAM, Y. Dynamics of complex systems. Readings, Massachusetts: Addison-Wesley, 1997.

BAUER, R. Gestão da mudança: caos e complexidade nas organizações. S. Paulo: Atlas, 1999.

BERTALANFFY, L. Teoria geral dos sistemas: aplicação à psicologia. In: Anohin, P.; Bertalanffy, L. (org.). Teoria dos sistemas. R. Janeiro: Editora da Fundação Getúlio Vargas, 1976. (série Ciências Sociais).

BERTALANFFY, L. Teoria geral dos sistemas, Petrópolis: Vozes, 1977.

BOULDING K. General systems theory: the skeleton of science. Management Science, v.2, n.3, p.197-208, 1956, reeditado em E:CO Special Double Issue, v.6, n.1-2, 
p.127-139, 2004.

CHECKLAND, P.; SCHOLES, J. Soft systems methodology in action. Chichester, West Sussex: John Wiley \& Sons, 1999.

CIRNE-LIMA, C. Causalidade e auto-organização, In: Cirne-Lima, C. e Rohden, L. (org). Dialética e auto-organização. S. Leopoldo: Editora da Unisinos, 2003 (Coleção Idéias).

COATS, A. Autopoiesis, estruturas dissipativas e processos históricos em economia. Estudos econômicos, v. 22, n.1, p.351-373, 1993.

DEMO, P. Complexidade e aprendizagem: a dinâmica nãolinear do conhecimento. S. Paulo: Atlas, 2002.

ENSSLIN, L.; MONTIBELLER, G; NORONHA, S. Apoio à decisão. Florianópolis: Insular, 2001.

GELL-MANN, M. The quark and the jaguar: adventures in the simple and complex. New York: W.H. Freeman and Company, 2000.

GLEICK, J. Caos: a criação de uma nova ciência. R. Janeiro: Campus, 1990.

GLEISER, I. Caos e complexidade: a evolução do pensamento econômico. R. Janeiro: Campus, 2002.

HOPEMAN, R. Análise de sistemas e gerência de operações. Petrópolis: Vozes, 1977.

HEYLIGHEN, F. Building a science of complexity. Proceedings of the 1988 Annual Conference of the Cybernetics Society London, 1988, disponível em http:// pespmc1.vub.ac.be/Papers/BuildingComplexity.pdf, acesso em janeiro/2006.

HUTCHINSON, D. Chaos theory, complexity theory and health care quality management. Quality Progress, v.77, n.1, p.2-9, 1994.

JACKSON, M. Systemic methods in management sciences. New York: Plenum Press, 1993.

KLIR, G. Facets of systems sciences. New York: Plenum Press, 1991.

KLIR, G. An approach to general systems theory. New York: Van Nostrand Reinhold Company, 1969.

LEITE, M.; BORNIA, A.; COELHO, C. A contribuição da teoria da complexidade à modelagem de sistemas. Anais do XXIV ENEGEP, Florianópolis, 2004.
LEWIN, R. Complexidade: a vida no limite do caos. R. Janeiro: Rocco, 1994.

LHOTE, F; CHAZELET, P.; DULMET, M. The extension of principles of cybernetics towards engineering and manufacturing, Annual Reviews in Control, 23, pg. 139$148,1999$.

LICATA, I. Intelligenza Artificiale: presentazione dell'area - prima parte. In: Il portale italiano sull'information. DisDisponível em: http:// www.programmazione.it/.Acesso em 10/07/2004.

MACIEL, J. Elementos de teoria geral dos sistemas. Petrópolis: Vozes, 1974.

MAXIMIANO, A. Teoria geral da Administração. S. Paulo: Atlas, 1997.

MCCARTHY, I. Manufacturing strategy: understanding the fitness landscape. International Journal of Operations \& Production Management, v.24, n.2, p.124$150,2004$.

MARKOSE, S. Computability and evolutionary complexity: markets as complex adaptive systems (CAS). The Economic Journal, v.115, n.504, p.159, 2005.

MORIN, E; LE MOIGNE, J. A inteligência da complexidade. S. Paulo: Fundação Peirópolis, 2000.

MORIN, E. Introdução ao pensamento complexo. Lisboa: Instituto Piaget, 1990.

PARKER, D.; STACEY, R. Caos, administração e economia: as implicações do pensamento não-linear. R. Janeiro: Instituto Liberal, 1995

PEAK, D.; FRAME, M. Chaos under control: the art and science of complexity. N. York: W.H. Freeman and company, 1994.

PERONA, M; MIRAGLIOTTA, G Complexity management and supply chain performance assessment. A field study and a conceptual framework. International Journal of Production Economics, v.90, n.3, p.103-115, 2004.

PRIGOGINE, I. The end of certainty: time, chaos and the new laws of nature. New York: Free Press, 1996.

RAPOPORT, A. Aspectos matemáticos da análise geral dos sistemas. In: Anohin, P. et al. Teoria dos sistemas. R. Janeiro: Editora da Fundação Getúlio Vargas, 1976. (série Ciências Sociais).

ROCHANETO, I. Gestão de organizações. S. Paulo:Atlas, 2003. 
RUELLE, D. Acaso e caos. S. Paulo: UNESP, 1993.

SENGE, P. A Quinta Disciplina. S. Paulo: Best Seller, 1990.

SELLITTO, M. Processos de pensamento da TOC como alternativa para análise sistêmica em organizações: um estudo de caso em saúde pública. Gestão \& Produção, v.12, n.1, p.81-96, 2005.

SELLITTO, M. Medição e controle de desempenho estratégico em sistemas de manufatura. Tese de doutorado. Engenharia de Produção, UFRGS, Porto Alegre, 2005a.

SELLITTO, M.; RIBEIRO, J.; PETRILLO, F. Modelo nãolinear de longo prazo para a potência requerida do sistema brasileiro de eletricidade. Investigação Operacional, v.27, n.1,p.1-20, 2007.

SELLITTO, M.; BORCHARDT, M.; PEREIRA, G. Avaliação numérica da complexidade organizacional de uma cadeia de suprimentos industriais. Anais do XXVIII ENEGEP. Foz do Iguaçu, 2007.

SELLITTO, M.; BORCHARDT, M.; PEREIRA, G. Avaliação numérica da complexidade organizacional de um recorte de uma rede pública municipal de serviços de saúde. Anais do XXIX ENEGEP. Rio de Janeiro, 2008.

SIMON, H. Architeture of complex systems. In: KLIR, G. (org.) Facets of systems sciences. New York: Plenum Press, 1991.

SOUZA FILHO, D. Iniciação à história da filosofia. R. Janeiro: Jorge Zahar, 2000.

STERMAN, J. Business dynamics: system thinking and modeling for a complex world. USA: McGraw-Hill, 2000.

THOMPSON, J. Modelos de organização e sistemas administrativos. In: Anohin, P.; Bertalanffy, L. (org.) Teoria dos sistemas. R. Janeiro: Editora da FGV, 1976.

\section{RECONHECIMENTO}

Os autores desejam reconhecer o meticuloso trabalho dos revisores, que muito contribuíram, com suas críticas e sugestões pertinentes, para que este artigo pudesse ser publicado. 